Abstract 254 Table 2 Summary of findings for maintenance therapy

\begin{tabular}{|c|c|c|c|c|}
\hline Comparison & Outcome & $\begin{array}{l}\text { Number of } \\
\text { participants (studies) }\end{array}$ & Relative risk & $\begin{array}{l}\text { Quality of the } \\
\text { evidence (GRADE) }\end{array}$ \\
\hline \multirow[t]{4}{*}{ Mycophenolate moletil Azathioprine } & Renal relapse & 452 (4 studies) & $0.63(0.42,0.95)$ & Moderate \\
\hline & Mortality & 452 (4 studies) & $0.87(0.26,2.94)$ & Very low \\
\hline & $\begin{array}{l}\text { End-stage kidney } \\
\text { disease }\end{array}$ & 452 (4 studies) & $0.75(0.28,2.04)$ & Very low \\
\hline & Major infection & 412 (3 studies) & $0.92(0.51,1.67)$ & Low \\
\hline
\end{tabular}

\section{PREDICTORS OF REMISSION AND LOW LUPUS DISEASE ACTIVITY STATUS (LLDAS): DATA FROM A MULTI- ETHNIC, MULTINATIONAL LATIN AMERICAN LUPUS COHORT}

\begin{abstract}
${ }^{1,2} \mathrm{M}$ Ugarte-Gil ${ }^{*},{ }^{3} \mathrm{D}$ Wojdyla, ${ }^{4} \mathrm{G}$ Pons-Estel, ${ }^{5} \mathrm{~J}$ Gomez-Puerta, ${ }^{6} \mathrm{~L}$ Catoggio, ${ }^{7} \mathrm{~A}$ Alvarellos, ${ }^{7} \mathrm{~V}$ Saurit, ${ }^{8} \mathrm{E}$ Borba, ${ }^{9} \mathrm{E}$ Sato, ${ }^{10} \mathrm{~L}$ Costallata, ${ }^{11} \mathrm{~N}$ Da Silva, ${ }^{12} \mathrm{~A}$ Iglesias-Gamarra, ${ }^{13} \mathrm{O}$ Neira, ${ }^{14} \mathrm{G}$ Reyes-Llerena, ${ }^{15} \mathrm{M}$ Cardiel, MC Amigo ${ }^{16},{ }^{1} \mathrm{E}$ Acevedo-Vasquez, ${ }^{17} \mathrm{M}$ Esteva-Spinetti, ${ }^{18} \mathrm{G}$ Alarcón, ${ }^{19} \mathrm{~B}$ Pons-Estel. ${ }^{1}$ Hospital Guillermo Almenara Irigoyen. EsSalud, Rheumatology, Lima, Peru; ${ }^{2}$ Universidad Científica del Sur, School of Medicine, Lima, Peru; ${ }^{3}$ GLADEL, Consultant, Rosario, Argentina; ${ }^{4}$ Hospital Clinic, Department of Autoimmune Diseases, Barcelona, Spain; ${ }^{5}$ Universidad de Antioquia, Facultad de Medicina-, Antioquia, Colombia; ${ }^{6}$ Hospital Italiano, Sección de Reumatología, Buenos Aires, Argentina; ${ }^{7}$ Hospital Privado, Servicio de Reumatología, Cordoba, Argentina; ${ }^{8} \mathrm{Hospital}$ das Clínicas da Faculdade de Medicina da Universidade de São Paulo, Rheumatology, São Paulo, Brazil, ${ }^{9}$ Universidade Federal de São Paulo, Departamento de Medicina, São Paulo, Brazil; ${ }^{10}$ Universidade Estadual da Campinas, Divisao de Reumatologia- Faculdade de Ciencias Medicas, Campinas, Brazil; ${ }^{11}$ Universidade Federal de Goiás, Faculdade de Medicina, Goiânia, Brazil; ${ }^{12}$ Universidad Nacional de Colombia, Facultad de Medicina, Bogotá, Colombia; ${ }^{13}$ Universidad de Chile, Facultad de Medicina, Santiago, Chile; ${ }^{14}$ Centro de Investigaciones Médico Quirúrgicas -CIMEQ-, Reumatología, Habana, Cuba; ${ }^{15}$ Centro de Investigación Clínica de Morelia, Reumatología, Morelia, Mexico; ${ }^{16}$ Centro Medico ABC, Reumatología, México, Mexico; ${ }^{17}$ Hospital Central de San Cristóbal, Reumatología, San Cristóbal, Venezuela; ${ }^{18}$ The University of Alabama at Birmingham, Department of Medicine, Birmingham, USA; ${ }^{19}$ Hospital Provincial de Rosario, Reumatologia, Rosario, Argentina
\end{abstract}

10.1136/lupus-2017-000215.255

Background and aims Remission and LLDAS prevent the occurrence of damage accrual in SLE patients. The aim of this study was to evaluate the predictors of remission and LLDAS in SLE patients.

Methods Three disease activity statuses were defined: Remission $=\mathrm{SLEDAI}=0$ and a prednisone dose $\leq 5 \mathrm{mg} / \mathrm{d}$ and/or immunosuppressive drugs in maintenance dose; LLDAS=SLEDAI $\leq 4$, a prednisone dose $\leq 7.5 \mathrm{mg} / \mathrm{d}$ and/or immunosuppressive drugs in maintenance dose; and non-optimally controlled status $=$ SLEDAI $>4$ and $/$ or prednisone dose $>7.5 \mathrm{mg} / \mathrm{d}$ and/or IS drugs in induction dose. Antimalarials were allowed in all groups. Patients with at least two SLEDAI reported and not optimally controlled at cohort entry were included in this analysis. Predefined outcomes were remission and remission/LLDAS. Potential predictors were gender, age at diagnosis, ethnicity, socioeconomic status, residence, health insurance, disease duration at cohort entry, organs/systems affected at or before cohort entry, treatment at or before cohort entry and SLEDAI at cohort entry. Univariable and multivariable Cox regression models with a stepwise selection procedure were performed for remission alone and for remission/LLDAS.

Results One-thousand one-hundred and forty patients were non-optimally controlled at cohort entry. One hundred and ninety-six patients achieved remission (17.2\%) and 314 achieved remission/LLDAS (27.5\%). Predictors of remission and remission/LLDAS in the multivariable models are depicted in Tables 1 and 2 .

Conclusions Mucocutaneous manifestations, renal involvement and higher disease activity early in the course of SLE were

Abstract 255 Table 1 Predictors of remission. Multivariable model.

\begin{tabular}{lll}
\hline Predictor & Hazard ratio $(95 \% \mathrm{Cl})$ & p value \\
\hline $\begin{array}{l}\text { Socioeconomic status } \\
\text { High/medium high }\end{array}$ & Ref. & \\
Medium & $0.856(0.543-1.348)$ & 0.5023 \\
Medium low/low & $0.626(0.407-0.961)$ & 0.0323 \\
Mucocutaneous involvement & $0.638(0.433-0.940)$ & 0.0230 \\
Renal involvement & $0.716(0.523-0.981)$ & 0.0373 \\
SLEDAl at baseline & $0.975(0.955-0.996)$ & 0.0188 \\
\hline
\end{tabular}


Abstract 255 Table 2 Predictors of remission/LLDAS. Multivariable model.

\begin{tabular}{lll}
\hline Predictor & Hazard ratio $(95 \% \mathrm{Cl})$ & p value \\
\hline $\begin{array}{l}\text { Prednisone dose (higher dose } \\
\text { before baseline) }\end{array}$ & \\
None & & \\
Low & Ref. & \\
Medium & $1.745(0.814-3.742)$ & 0.1527 \\
High & $1.559(1.081-2.247)$ & 0.0174 \\
Very high & $0.891(0.668-1.188)$ & 0.4315 \\
Mucocutaneous involvement & $0.652(0.474-0.898)$ & 0.0089 \\
Renal involvement & $0.686(0.532-0.884)$ & 0.0036 \\
SLEDAl at baseline & $0.979(0.962-0.996)$ & 0.0170 \\
\hline Prednisone dose: Low dose: $<7.5 \mathrm{mg} / \mathrm{d}$, medium dose: $: 7.5-15 \mathrm{mg} / \mathrm{d}$, high dose: $15-60 \mathrm{mg} / \mathrm{d}$, very high dose $: 260 \mathrm{mg} / \mathrm{d}$
\end{tabular}

associated with a reduced risk of remission and remission/ LLDAS; lower socioeconomic status was associated with a reduced risk of remission. A medium prednisone dose was associate with an increased risk of remission/LLDAS.

\section{THE EFFECT OF ADDING CURCUMIN ON VITAMIN D3 SUPPLEMENTATION ON THE DISEASE ACTIVITIES AND FATIQUE DEGREE IN SLE PATIENTS WITH HYPOVITAMIN D}

${ }^{1} \mathrm{CS}$ Wahono*, 'ZD Wahyuni, ${ }^{1} \mathrm{CD}$ Setyorini, ${ }^{1}$ I Saveria, ${ }^{2} \mathrm{~K}$ Handono, ${ }^{1} \mathrm{H}$ Kalim. ${ }^{1}$ Universitas Brawijaya/Saiful Anwar Hospital, Internal Medicine, Malang, Indonesia; '2Universitas Brawijaya/Saiful Anwar Hospital, Clinical Pathology, Malang, Indonesia

\subsection{6/lupus-2017-000215.256}

Background and aims Vitamin D has important roles in the regulation of the immune system in Lupus. Seventy percent of lupus patients in Indonesia are experienced hypovitamin D. Curcumin is a natural VDR ligand and has sinergic effect with vitamin D. This study was aimed to determine the effect of adding curcumin on vitamin D supplementation on the degree of disease activity and degree of fatigue, in SLE patients with hypovitamin D.

Methods This was a randomised controlled trial, double blind study. Forty SLE patients with hypovitamin D were studied, that randomizeded into two groups: 20 patients (supplementation group) received vitamin D (cholecalciferol 1200 IU daily) with curcumin $20 \mathrm{mg}$ (three times daily); and 20 patients (placebo group) was given vitamin D (cholecalciferol 1200 IU daily) and placebo ( 3 times daily), for 3 months. Disease activity is determined by the SLEDAI scores and the degree of fatigue is determined by the FSS (Fatigue Severity Scale).
Results After supplementation for 3 months, this study showed that decreased of SLEDAI score in the supplementation group was greater than the placebo group. The decreased of FSS in the supplementation group was also greater than the placebo group.

Conclusions Adding curcumin on vitamin D supplementation, decreased SLEDAI scores and FSS greater than vitamin D supplementation plus placebo in SLE patients with hypovitamin D.

\section{THE EFFECT OF ADDING CURCUMIN ON VITAMIN D3 SUPPLEMENTATION ON ANTI-DSDNA LEVELS AND PROTEINURIA, IN SLE PATIENTS WITH HYPOVITAMIN D}

${ }^{1} \mathrm{CS}$ Wahono, ${ }^{2} \mathrm{H}$ Susianti ${ }^{*},{ }^{1} \mathrm{ZD}$ Wahyuni, ${ }^{1}$ I Saveria, ${ }^{1} \mathrm{CD}$ Setyorini, ${ }^{2} \mathrm{~K}$ Handono, ${ }^{1} \mathrm{H}$ Kalim. 'Universitas Brawijaya/Saiful Anwar Hospital, Internal Medicine, Malang, Indonesia; ${ }^{2}$ Universitas Brawijaya/Saiful Anwar Hospital, Clinical Pathology, Malang, Indonesia

\subsection{6/lupus-2017-000215.257}

Background and aims Vitamin D has important roles in the regulation of the immune system in Lupus. Seventy percent of lupus patients in Indonesia are experienced hypovitamin D. Curcumin is a natural VDR ligand and has sinergic effect with vitamin $\mathrm{D}$. This study was aimed to determine the effect of adding curcumin on vitamin D supplementation on antidsDNA serum levels and proteinuria, in SLE patients with hipovitamin D.

Methods This was a randomised controlled trial, double blind study. Forty SLE patients with hypovitamin D were studied, that randomised into two groups: 20 patients (supplementation group) received vitamin D (cholecalciferol 1200 IU daily) with curcumin $20 \mathrm{mg}$ (three times daily); and 20 patients (placebo group) was given vitamin D (cholecalciferol 1200 IU daily) 